\title{
ANAESTHESIA FOR THE PATIENT WITH MULTIPLE INJURIES: SOME PROBLEMS CONCERNING ANAESTHETIC MANAGEMENT ILLUSTRATED BY A CASE REPORT*
}

\author{
W. E. SPOEREI, M.D., F.R.C.P. (c) ${ }^{\dagger}$
}

WrTH an apparent increasing frequency patients come to the hospital who are badly "smashed up"; automobile accidents, industrial accidents, mishaps on the farm, are the causes, and with the help of modern resuscitation methods these patients reach a hospital. Here they present an awkward problem. In smaller hospitals the medical staff provides an excellent resuscitation service, but facilities and experience for definitive care are usually lacking. Large hospitals have a highly specialized staff, but it is often difficult to organize the team of specialists required to deal with the patient's manifold problems. On occasion the patient will have to possess sufficient reserves to survive misguided but wellmeant diagnostic and therapeutic efforts, depending on whether he is first seen by a neurosurgeon, a general surgeon, an internist, or a psychiatrist.

The anaesthetist frequently becomes involved only after other consultants have made the decision for active treatment. This is often several hours after the accident and, unless he has been properly cared for, the patient's condition may have deteriorated. The anaesthetist is then confronted, on short notice, with a baffling and complex problem; presented with a bundle of maimed flesh and broken bones, he finds it difficult to decide where to begin and how to continue.

Using a particular case and its management as a practical illustration this paper proposes to discuss some general principles and common problems as they arise in the patient's story.

A 52-year-old janitor of a district high school on the Niagara Peninsula was a known epileptic, but well controlled on drugs. On July 30, while cleaning windows, he slipped and fell about 50 feet onto the school yard. With multiple fractures and in severe shock he was rushed to the local hospital, where he received 21 units of blood during the next 30 to 40 hours. Bleeding indicated damage to the urethra and bladder, and a suprapubic cystotomy was performed, but no urine was obtained. Attempts to secure admission for the patient to a larger hospital failed; the situation was considered hopeless and transport futile. Through the mediation of a consultant from our area, who incidentally visited that hospital on August 1, the patient was transferred to Victoria Hospital in London. He was admitted the same day with the diagnosis of multiple fractures and anuria and was referred to the nephrologist. However, an anaesthetist had also been alerted about this man's arrival and both were called when the patient arrived.

The patient with multiple injuries requires a team approach, and the anaesthetist, as a member of this team, should be called in early and not only at the

- Presented at the Annual Fall Meeting of the Section on Anaesthesia, Ontario Medical Association, Hamilton, Ontario, October 14 and 15, 1966.

tDepartment of Anaesthesia, University of Western Ontario, London, Ontario. 
time the decision is made to operate. He should actually see the patient together with or even before the surgeon and other consultants. He is most qualified to institute or continue resuscitation, to deal with life-threatening problems such as airway obstruction or respiratory failure, and to find an access route to the circulatory system in a hurry. For many patients these services may be far more important than the subsequent decision of a specialist to open the patient's abdomen, to do an angiogram, or to deal with a fractured femur.

In order to be called early for the assessment and care of such patients, not only is it important that the anaesthetist sell this concept to other specialists, but he also must educate himself and develop an active interest in the care of traumatized patients. It may be a matter of life or death for the patient whether the anaesthetic care has begun when the patient arrived in the emergency room or only after the patient finally reached the operating room. It must be emphasized that the anaesthetic management of the patient should begin at the time of admission and that the care of the patient in the operating room is only one phase of it. The anaesthetist must extend his care into the preoperative and postoperative periods to an extent proportional to the severity of the patient's condition.

The patient presented a number of obvious findings: He was unconscious; he had shallow, jerky, noisy respiration; he looked gray and pale and had a rapid heart rate $(120 / \mathrm{min}$.) and a low blood pressure $(98 / 54 \mathrm{~mm} . \mathrm{Hg})$. The suprapubic tube was attached to a dry container. Several of the numerous fractures were quite obvious; both legs and right upper arm were fractured, and a supraorbital fracture caused a deformity of the left orbit with considerable swelling. The patient also had multiple pelvic fractures and fractures in several metatarsal bones; a later X-ray gave evidence of a large retroperitoneal haematoma.

The anaesthetist's initial reaction is to support the patient's airway, first manually and then by positioning or by the use of mechanical devices. In our patient the respiration improved when the jaw was raised, and the air exchange increased significantly; with the increased air flow, however, loud rhonchi and gurgling noises could be heard, indicating the necessity for suction of the pharynx and trachea.

The patient was intubated and large amounts of tenacious blood-tinged mucus were sucked out, followed by a substantial improvement of the air exchange.

The unconscious patient, whose cough reflex is suppressed centrally, or peripherally by fractures and injuries to the chest wall, may accumulate secretions in the pharynx and trachea. Blood, mucus, and other debris is often aspirated from the nasopharynx, stagnates in the tracheo-bronchial tree, becomes infected, and in turn contributes to the patient's demise. In this type of patient it is best to adopt an active attitude immediately, intubating the trachea and applying suction through the tube. This should be the first approach; a bronchoscopy may be required later if specific indications exist, such as a persisting atelectasis or a suspected foreign body.

While intubating to establish a patent airway, the anaesthetist should remember that he should be an eminent specialist in the assessment of unconscious states. 
A laryngoscopic examination will give a valuable indication of how deeply unconscious the patient is. Both the insertion of the laryngoscope and the introduction of a tube through the glottis into the trachea are selective stimuli, and the presence or absence of responses should be noted. This is so revealing that I am convinced we should attempt to intubate every patient we see in an unconscious state. There are many surprises; regardless of other criteria, the patient who can be intubated without objecting much probably needs to have his airway protected by an endotracheal tube.

Following intubation the patient had an apparently adequate tidal volume and his breathing was unobstructed; however, his colour failed to improve and in spite of repeated tracheal suction he remained quite cyanosed. There were no paradoxical chest movements; auscultation revealed good air entry over all lung fields. Augmentation of the respiration with air (Ambu resuscitator) and inhalation of oxygen did not produce a significant change.

In a patient with a blunt trauma to the body and the chest, one must always be prepared for the unexpected. Pneumothorax is a common and treacherous problem. It can occur without recognizable rib fractures. Haematothorax, rupture of diaphragm, pericardium, or a bronchus, and even of the aorta have occurred without demonstrable damage to the chest wall.

The initial absence of indications of such injuries is no reassurance; in particular a pneumothorax may occur suddenly many days after the original injury. This was demonstrated to us recently by a patient who sustained fractured ribs and a fractured patella. After ten days, with the patient in seemingly good condition, it was decided to operate on the patella. On return from the operation the patient complained of increasing dyspnoea; a tension pneumothorax was only discovered when the patient had a sudden cardiac arrest from which he was successfully resuscitated after pleural drainage.

A portable chest X-ray (Fig. 1) showed both lungs expanded but a generalized patchy density over all lung fields. Blood gas determination gave an arterial $\mathrm{P}_{\mathrm{O}_{2}}$ of $33 \mathrm{~mm} . \mathrm{Hg}$ (while the patient was ventilated with air), a $\mathrm{P}_{\mathrm{CO}_{2}}$ of $31.5 \mathrm{~mm} . \mathrm{Hg}$, and a $\mathrm{pH}$ of 7.42 .

The patient was subsequently ventilated with a Bird respirator driven by compressed oxygen (inspired oxygen concentration 60 to 70\%.1 Under this management the measurements shown in Table I were obtained a day later.

Table I shows that the patient required a large respiratory minute volume to maintain a normal carbon dioxide tension and that even with two-thirds of this inspired volume being oxygen, his arterial oxygen tension was barely normal. The disturbance of his pulmonary function had caused not only an increase of dead-space but also a considerable shunting of venous blood across the lungs to the arterial side.

The reason for this respiratory problem could be twofold: (1) With fractures of long bones, fat embolism is frequent and could be severe with the number of fractures present in this patient. (2) Blunt trauma to the chest, even in the absence of other injuries, may cause extensive pulmonary contusion or what one may colloquially call "bruising of the lung." The changes in the lung consist of disruption of alveoli, interstitial haematoma, and oedema. 


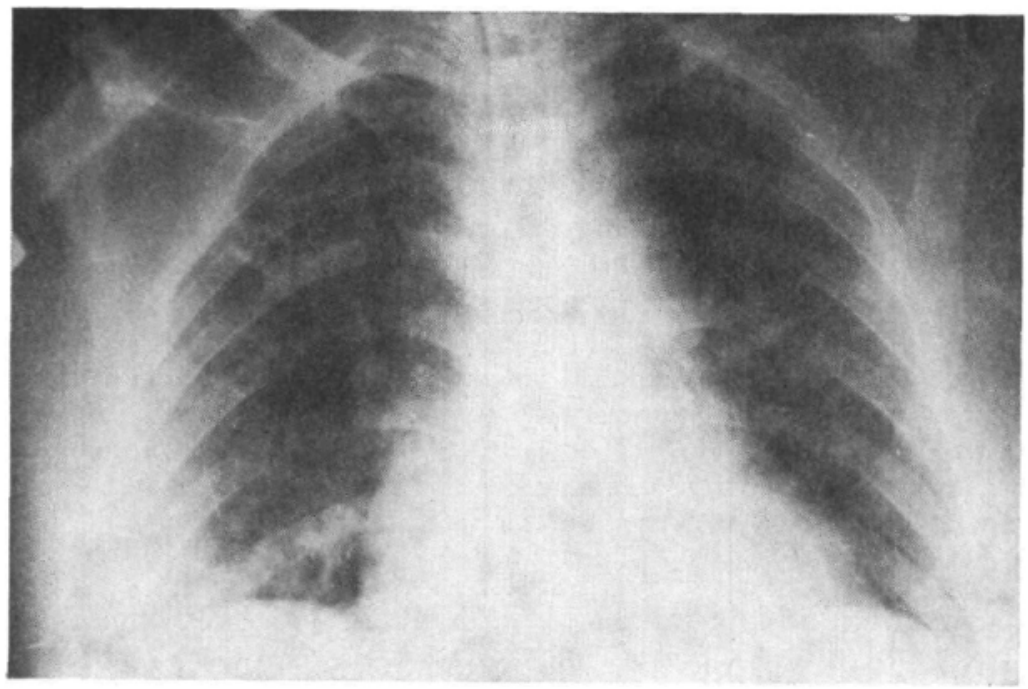

Frgone 1

The clinical characteristics of this injury are dyspnoea, a low arterial oxygen tension, and the presence of blood-tinged secretions in the tracheobronchial tree. $^{2}$ The $\mathrm{X}$-ray findings are initially a diffuse density. Later they may be difficult to distinguish from either fat embolism or widespread aspiration pneumonitis, although the latter is often confined to the lower lobes, or more extensive there.

Pulmonary contusion can occur in the absence of any other demonstrable injuries. This was shown in a 17-year-old boy who was admitted following a severe blow to the upper chest in an accident. He was dyspnoeic and cyanosed, and his chest X-ray (Fig. 2) revealed a density in both upper lung fields while the bases of both lungs were clear. He was managed with oxygen only and made an uneventful recovery.

Severe dyspnoea is associated with a high activity of the upper abdominal muscles, and this often makes the examination of the abdomen difficult. Prompt treatment of the respiratory problem may therefore be of great importance for the diagnosis of a possible intra-abdominal injury. Even in the absence of abdomi-

TABLE I

Respiratory Data

\begin{tabular}{|c|c|c|c|c|c|c|c|}
\hline Date & Management & $\underset{(\mathrm{mm} \cdot \mathrm{Hg})}{\mathrm{Po}_{2}}$ & $\underset{(\mathrm{mm} \cdot \mathrm{Hg})}{\mathrm{P}}$ & $\mathrm{pH}$ & $\begin{array}{l}\text { Resp. } \\
\text { rate }\end{array}$ & $\begin{array}{l}\text { Resp. } \\
\text { minute } \\
\text { volume } \\
\text { (L.) }\end{array}$ & $\begin{array}{c}\text { Tidal } \\
\text { volume } \\
\text { (ml.) }\end{array}$ \\
\hline Aug. 1 & $\begin{array}{l}\text { Endotracheal tube; ventilated } \\
\text { with air }\end{array}$ & 33 & 31.5 & 7.42 & & & \\
\hline Aug. 2 & $\begin{array}{l}\text { Tracheostomy; Bird Respira- } \\
\text { tor }\left(\mathrm{O}_{2}\right)\end{array}$ & 84 & 39 & 7.39 & 19/min. & 15.2 & 800 \\
\hline
\end{tabular}




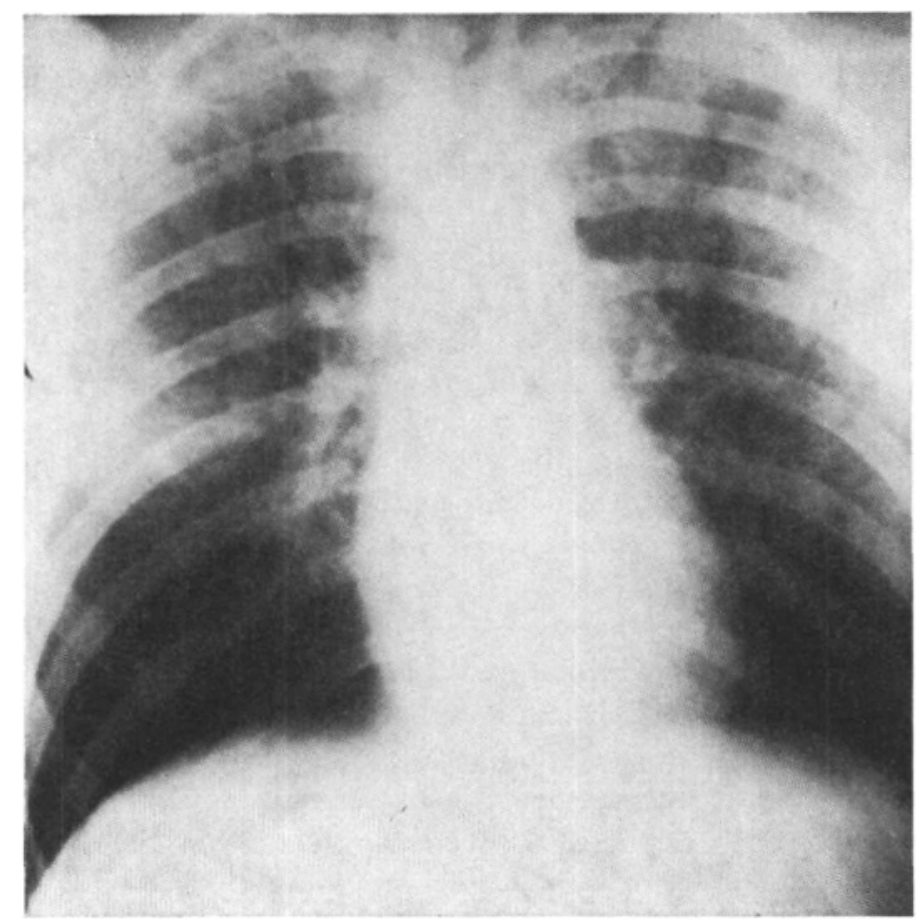

Figure 2. Pulmonary contusion in both upper lung fields.

nal injuries we must keep in mind that patients in shock and after trauma have a marked inhibition of gastric motility. With facial injuries they have often swallowed quantities of blood and air. Dyspnoea, particularly when associated with a high negative intrathoracic pressure, facilitates the indrawing of air into the oesophagus. The likely result is a distended stomach, partially filled with fluid. Vomiting or regurgitation are likely when sedatives are used or when the patient is anaesthetized. It is therefore advisable to pass a plastic stomach tube at the earliest convenient time.

Even with improved oxygenation the patient's pressure remained low and he had a rather rapid heart rate, indicating possible hypovolaemia. The results of laboratory examinations done shortly after admission are shown in Table II. The patient was anaemic and for his size (he is a very muscular patient weighing $91 \mathrm{~kg}$.), he had a low blood volume. There had not been an external haemorrhage of any significance. The patient's extremities were markedly swollen, and the only normal extremity was puffed up by an accidental interstitial infusion.

Large volumes of blood can extravasate into tissues, and in spite of the infusion of 21 units of blood the patient was still hypovolaemic. On the other hand, in the absence of renal function, volume replacement must be undertaken cautiously to avoid overloading the circulation; patients with pulmonary contusions are prone to develop pulmonary edema.

The first practical problem, however, is the establishment of an intravenous 
TABLE II

Laboratory Data

\begin{tabular}{lc}
\hline \hline Haemoglobin (gm.\%) & $\mathbf{8 . 5}$ \\
Haematocrit & 22 \\
Plasma volume (ml.) & 4330 \\
Blood volume (ml.) & 5600 \\
B.U.N. (mg. \%) & 84 \\
K (m. Eq.) & 6.5 \\
Na (m. Eq.) & 135 \\
Cl (m. Eq.) & 925 \\
\hline
\end{tabular}

infusion in the absence of a suitable vein in an extremity. Under such circumstances special attention should be paid to the external jugular vein, ${ }^{3}$ which is often easily accessible and allows rapid infusion, as it does not constrict in response to irritation. The external jugular vein can be made visible in most patients, even when they are hypovolaemic, by tilting the patient slightly, head down. The technique of puncture is easily learned, and a plastic needle can be maintained in the neck (Fig. 3) and used for intravenous infusion for several days.

At the same time we can measure venous pressure at this location. There is essentially no difference between the venous pressure in the external jugular vein and that in the superior vena cava, providing that a proper baseline is

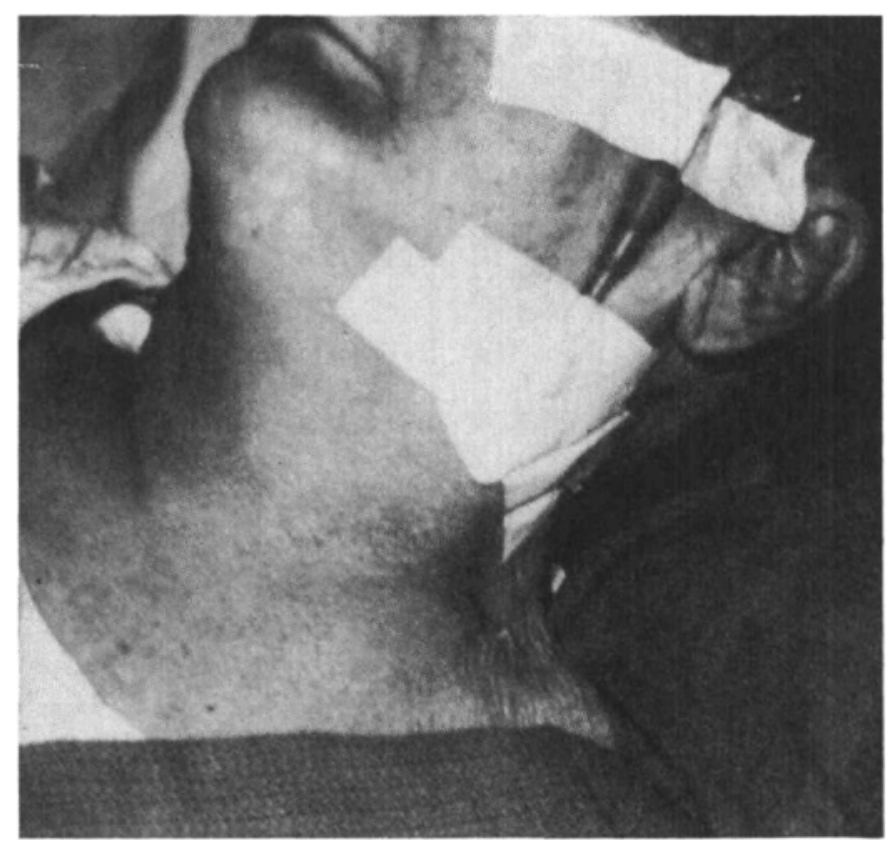

Figurs 3. Intravenous infusion into the external jugular vein (fourth day). 
observed. Although the technique of using a long catheter advanced into the superior vena cava is advocated by many writers, we have found this simpler technique equally useful. In the assessment of a patient, monitoring of the venous pressure is a most useful indicator for blood replacement and a safeguard against overtransfusion." Should a venipuncture fail, then a cut-down is indicated, preferably in the upper extremities or in the neck. In a leg, particularly in patients with peripheral vasoconstriction who may require large volumes of blood, a cut-down is unsatisfactory owing to the often extreme constriction in the leg veins. If one has to resort to a cut-down in this type of patient, it would be preferable to introduce a long plastic catheter into the basilic vein and advance it into the upper vena cava to be able to record venous pressure. ${ }^{4}$

Until cross-matched blood becomes available the infusion of low molecular dextran appears at present to be the best alternative. Low molecular dextran up to one litre does not interfere measurably with the clotting mechanism and does not disturb the identification of blood groups; it causes a transient increase in plasma volume and is said to improve peripheral blood flow by lowering blood viscosity. Even in the face of considerable anaemia, as in our patient, volume expansion seems preferable to the use of vasopressors. However, great caution must be used if the patient has apparently no urine output; also his main problem is one of oxygen uptake and transport, and therefore the deficit in blood volume is best replaced with whole blood. If the patient responds satisfactorily to oxygenation and volume replacement, other supportive measures often used in conjunction with shock, such as vasodilators, Isuprel, cortisone, or even digitalis are probably not indicated. There has been a tendency recently to assume the presence of a metabolic acidosis following prolonged hypoxia or hypotension and to administer sodium bicarbonate in such patients routinely. As the blood gas determinations have indicated, our patient had no metabolic acidosis in spite of a severe insult; the uncontrolled use of sodium bicarbonate may have adverse effects in the absence of renal function.

With controlled ventilation and following the infusion of two units of blood the patient had improved considerably. Dialysis was not required immediately. There was no indication for a neurosurgical intervention and there appeared to be no intrathoracic or intra-abdominal injuries requiring surgical intervention. It was planned to do a tracheostomy and to stabilize the leg fractures by traction.

This is a good, safe, conservative approach. However, the anaesthetist as a member of the team should enter this discussion since he will have to keep the patient alive throughout whatever procedure is decided upon. In general any procedure that can safely be done later should be postponed. All procedures should be carried out that restore the function of vital organs as well as those that arrest processes which become detrimental with the passage of time. Obviously any demonstrable haemorrhage should be arrested, and a ruptured viscus must be attended to as soon as possible. In this particular case we felt the immediate examination of the upper urinary tract under the same anaesthetic would be indicated on the basis that the patient had not produced any urine since the accident, and on the $X$-ray evidence of a retroperitoneal haematoma 
which, when seen by the radiologist, must be considerable. Thus a urologist was added to the list of consultants and the patient was moved to the operating room for a tracheostomy, balanced traction of both legs, cystoscopy, and a retrograde pyelography.

The anaesthetist who is called in only at the time the patient arrives in the operating room is at a severe disadvantage and represents a hazard to the patient. If he has been taking part in the management of the patient up to this point, the anaesthetic procedure itself is probably not a major undertaking. The basic principle is to administer just enough of any suitable anaesthetic agent to satisfy the surgeon's requirements. In view of the pulmonary contusion it may be best to use oxygen only and not a nitrous-oxide-oxygen mixture. Thiopentone should be used in minimal doses. Halothane in oxygen ( 0.5 to $1.0 \%$ ) would be a good choice. Should a fall in blood pressure occur it is likely due to continued bleeding and a low blood volume, and further blood replacement is indicated. Again the venous pressure should give valuable information.

Innovar was chosen for the anaesthetic management beginning with an intravenous injection of $2 \mathrm{ml}$. of the conventional solution $(5 \mathrm{mg}$. of droperidol and $0.1 \mathrm{mg}$. of phentanyl) and adding about $1 \mathrm{ml}$. of this mixture whenever the patient responded to stimuli; the patient was ventilated with 100 per cent oxygen. Under this management a cystoscopy was performed and catheters were introduced into both ureters. The retrograde pyelogram showed a dilated, intact renal pelvis on both sides, and urine containing $2 \mathrm{gm}$. per cent haemoglobin flowed from both kidneys. This finding of course improved the patient's prognosis considerably and encouraged us to continue our efforts. With additional increments of Innovar (a total of $18 \mathrm{mg}$. droperidol and $0.36 \mathrm{mg}$. phentanyl) and $12 \mathrm{mg}$. of d-tubocurarine, stabilization of the fractures was undertaken, and finally the endotracheal tube was changed to a cuffed tracheostomy tube to continue ventilation postoperatively.

Innovar, consisting of a 1 to 50 mixture of phentanyl and droperidol, appears to be a very useful agent under these circumstances, as it produces a state of non-reactivity in the patient without circulatory depression if sufficiently small doses are used.

We have been able to intubate severely restless and dyspnoeic patients easily with the help of Innovar. Particularly in patients with severe facial injuries, where it was not possible to apply a mask, and therefore dangerous to use muscle relaxants, we were able to carry out intubation safely without haste in a spontaneously breathing patient. In conscious patients the judicious addition of small doses of thiopentone (100-200 mg.) facilitates induction and appears preferable to the use of larger doses of Innovar. ${ }^{5}$

The anaesthetist's care should continue into the postoperative period, particularly in regard to the maintenance of an adequate airway, adequate ventilation, and monitoring of the circulation. These patients should not be left alone; they need at least the attendance of an experienced nurse, and an anaesthetist or another physician experienced in resuscitation and the care of postoperative patients should be available on a moment's notice. Life-threatening complications such as pneumothorax, atelectasis, haemorrhage, or the ever-present danger of airway obstruction may arise suddenly; more frequently, there is an insidious development of a complication ending in a sudden disaster unless it is recognized 
early. The patient's survival depends on astute and rapid diagnosis and active treatment of complications.

Postoperatively the patient was admitted to the intensive care unit. He had a stormy course over the next few days, the main problems being anaemia, the maintenance of a precarious urinary drainage, a worrisome paralytic ileus, and intermittent respiratory difficulties. He received eight additional units of blood during the first 48 hours after his admission and 7 more units during the following four weeks to maintain a haemoglobin above $10 \mathrm{gm}$. per cent. The patient became severely jaundiced due to the breakdown of extravasated blood; his bilirubin reached a peak of $28 \mathrm{mg}$. per cent 12 days after admission without evidence of impairment of liver function. He required respiratory assistance for 38 days. Subsequently several corrective orthopaedic procedures were done, and he left the hospital after $7 \%$ months walking with a cane.

\section{SUMMARY}

Patients with multiple injuries present complex and challenging problems to the anaesthetist. Constant vigilance and rapid recognition and treatment of complications are essential. The anaesthetist should be a member of the team that manages the patient and should attend the patient from the time of his admission to hospital. He should be actively interested in the management of severely traumatized patients and become familiar with the recognition and management of complications affecting parameters of ventilation and circulation.

The presence of pulmonary contusion and the often severe reduction in oxygen tension caused by this condition should be considered in every case of unexplained dyspnoea and cyanosis. Pneumothorax is an ever-present danger. Assessment of the venous pressure is extremely helpful for the management of circulatory problems. The external jugular vein is a readily accessible avenue for infusion. Enormous extravasations can occur and require massive replacement of blood; low molecular weight dextran may be useful initially. Surgical procedures must be aimed at restoration of vital functions and the prevention of further damage. Intensive therapy is required postoperatively for prolonged periods, and in this the anaesthetist plays an important role.

For the anaesthetic management, minimal anaesthesia with high oxygen concentrations should be used. In our experience Innovar can be very satisfactory under these circumstances.

\section{RÉSUMÉ}

Les porteurs de blessures multiples présentent à l'anesthésiste des problèmes complexes et une sorte de défi. Il lui faut exercer une constante vigilance, faire le diagnostic et le traitement précoces des complications. L'anesthésiste doit faire partie de l'équipe qui traite le malade et doit examiner le malade dès son admission à l'hôpital. Il doit manifester un intérêt actif dans le traitement des grands blessés et s'entrainer à dépister et à traiter toutes les complications susceptibles d'affecter la ventilation et la circulation.

Tous les cas de cyanose ou les cas de dyspnée sans causes apparentes doivent faire penser, dans ces circonstances, à la présence d'une réduction marquée de la 
tension en oxygène dans les poumons et d'une contusion pulmonaire. Le pneumothorax est une possibilité constante.

En ce qui concerne les problèmes de la circulation, l'évaluation de la pression veineuse est très précieuse. La veine jugulaire externe est une voie d'accès facile pour les infusions. Il peut survenir des extravasations considérables qui nous obligent à administrer de grandes quantités de sang: au début, le dextran à faible poids moléculaire peut nous être utile. Les opérations doivent avoir pour but: le rétablissement des fonctions vitales et la prévention de dégats plus grands. Après l'opération, ces malades exigent des soins intensifs durant de longues périodes et c'est là que l'anesthésiste joue un rôle important.

$\mathrm{Au}$ cours de l'anesthésie, il est préférable de donner une anesthésie légère et une concentration élevée en oxygène. Dans de semblables circonstances, à notre avis, l'innovar peut rendre de précieux services.

\section{REFERENCES}

1. Fairlex, H. B. \& Britr, B. A. The Adequacy of the Airway Control in Ventilators Operated from an Oxygen Source. Canad. M. A. J. 90: 1394 (1964).

2. Alfonso, G. S. \& Hale, H. W., JR. Pulmonary Contusion. J. Trauma, 5: 647 (1965).

3. KeznLeyside, H. B. External Jugular Vein for Rapid Transfusion during Surgery. Canad. Anaesth. Soc. J. 9: 512 (1962).

4. Jenkrns, L. C. \& Screzch, G. Central Venous Pressure Monitoring in Anaesthesia. Canad. Anaesth. Soc. J. 13: 513 (1966).

5. Spoerer, W. E. \& Chan, W. S. Innovar in Surgical Anaesthesia. Canad. Anaesth. Soc. J. 12: 622 (1965). 